\title{
Una nova visió dels patis escolars
}

\section{Carme Cols i Pitu Fernàndez*}

Resum

L'espai del pati és una finestra oberta al món. El seu plantejament ens permet intuir la vida de l'escola des de punts de vista i aspectes diferents. És un dels primers espais en què les famílies es fixen per escollir escola. Un espai emotiu per les percepcions i els records que la majoria dels adults han viscut. És un espai comunitari i una porta oberta a la participació en el municipi com a territori col.lectiu. Pot ser un lloc en el qual la naturalesa articuli i faci visibles diferents zones, convidant a ser habitat i oferint la possibilitat de compartir experiències en un ambient ric en possibilitats de joc, d'aprenentatge, de relacions, de convivència, de creativitat. Un espai de vida i per a la vida en el qual apostem per fer possible una escola agradable, on nens, mestres i famílies es trobin bé, tant en l'espai interior com a l'exterior de l'escola.

\section{Paraules clau}

Espai educatiu, pati escolar, organització, comunitat educativa, natura, paisatgisme, arquitectura

Recepció original: 6 d'octubre de 2020

Acceptació: 10 de març de 2021

Publicació: 1 de juny de 2021

\section{Observar realitats i prenent consciència de la situació}

Davant la concepció tradicional del pati, passar a considerar-lo com un espai educatiu, requereix necessàriament un treball i una formació conjunta de la comunitat educativa per compartir el canvi de mirada. Com a mestres, ja jubilats, ens motiva poder continuar coneixent diferents realitats en els patis de les escoles. Què passa en aquests espais? Com son ocupats? Per què es produeixen conflictes? Per què la natura s'ha allunyat d'ells? Per què estan tan descuidats? Per què s'està generat tant interès en la seva transformació? Es parla només de disseny o de donar resposta a les necessitats educatives? De què parlen els projectes educatius? S'està plantejant pedagògicament la seva utilització? Com incideix la formació?

(*) Carme Cols i Pitu Fernàndez son una parella pedagògica i en la vida real, mestres de tota la vida a l'escola infantil i primària, actualment jubilats. L'any 2000 van crear el projecte El Safareig, un espai de diàleg i comunicació sobre infància i naturalesa a Internet: elsafareig.org. Des de llavors, la recerca sobre aquest tema els ha portat a acompanyar a centenars d'escoles considerant les moltes oportunitats que ofereixen els patis escolars com a espais de joc i aprenentatge. Aprenent i compartint sobre el que representen els seus espais, la pedagogia i l'arquitectura, escenaris on viuen i conviuen les comunitats educatives. Són promotors del grup de treball Com està el pati, de l'AM Rosa Sensat i de l'associació d'àmbit estatal Patios Habitables. Han organitzat i participat en diversos viatges per països d'Europa i Amèrica per conèixer els seus sistemes educatius fixant la seva atenció sobre els patis escolars. El 2015 van crear el blog: elnousafareig.org sobre l'espai exterior de l'escola com a espai educatiu. Adreces electròniques: ccols@xtec.cat / jfernanq@xtec.cat 

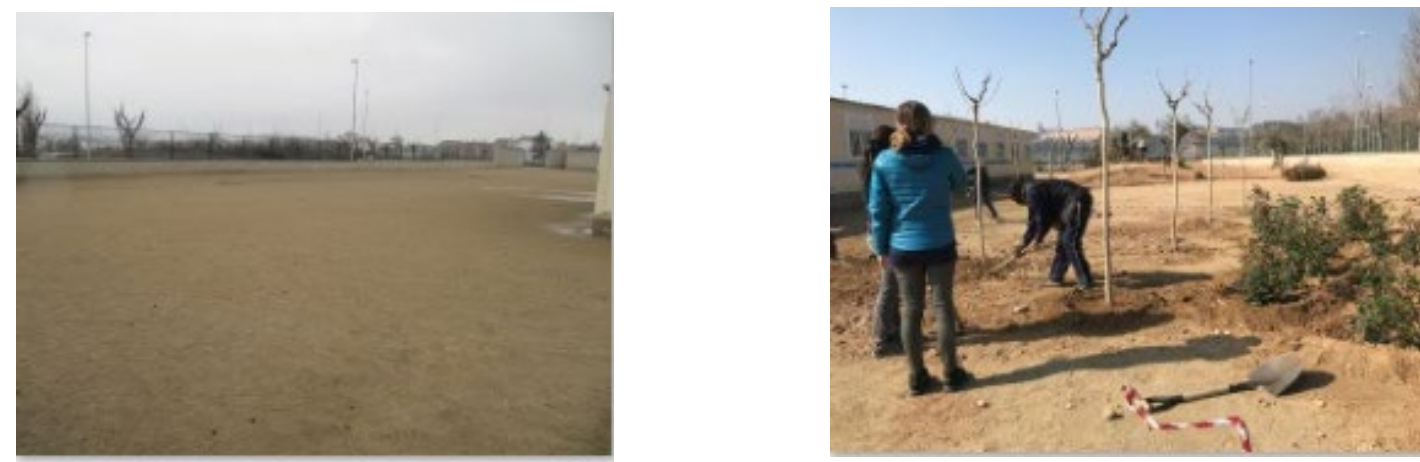

Diferents mirades amb actitud positiva creient en fer possibles els canvis necessaris per donar resposta a moltes de les preguntes anteriors i formular-nos unes de noves. En aquesta tasca, hem acompanyat moltes escoles preocupades per aquest tema al costat de les que hem pogut conèixer molt de prop l'estat de la qüestió i ajudar a imaginar una altra visió de funcionalitat dels espais. De formes molt diverses, hem vist com estan actuant per donar resposta als diferents reptes i necessitats que suposa un procés de transformació que va més enllà d'un disseny o posar «coses».

Pensar els espais de l'escola ens fa recuperar la reflexió d'Adolf Ferrière:

El nen estima la natura i se l'amuntega en sales tancades; li agrada donar un objectiu a les seves activitats i l'hi hem tret; li agrada moure's i I'hem immobilitzat; li agrada parlar i I'hem fet callar; volia raonar i ens dirigim només a la seva memòria; volia seguir la seva fantasia i l'hem impulsat a fugir; volia ser lliure i l'hem ensenyat a obeir passivament (Ferrière, 1929, p. 16).

Un pensament que ens interroga. Com són els espais i què passa en ells? Com ha de ser l'escola de la infància i per a la infància? És possible una escola agradable, on es trobin bé els nens i les nenes, mestres i famílies? Quin tipus d'organització pot fer possible utilitzar el temps d'una altra manera? Quines són les estratègies per intensificar les relacions i el coneixement? Com potenciar la pedagogia de l'escolta i de les relacions? Tecnologia i naturalesa es complementen? El joc Iliure, l'esport, el teatre, la música poden conviure en un espai organitzat i pensat? Prohibir la pilota és beneficiós? La tasca de pensar, parlar, discutir, d'intercanviar en la formació i en la pràctica ens va ajudant a definir el concepte d'escola, d'infància, des del punt de vista teòric i pràctic, amb un nou imaginari, per veure els patis com un lloc més enllà dels trenta minuts d'esbarjo.

Un gran treball i molts reptes en el qual l'articulació de tots els espais representa un dels aspectes fonamentals per poder repensar horaris amb flexibilitat, en definitiva, per poder pensar en donar resposta a la seva funcionalitat i a les metodologies. Escoltant $i$ observant a centenars d'escoles en els seus processos, hem pres consciència de la complexitat de realitats i de les seves confusions. Cada escola és un món i requereix temps de trobades i debats dels equips pedagògics, coneixedors de les seves necessitats educatives, elaborant criteris i implicant als diferents sectors de la comunitat: infants, famílies i institucions. La realització de petits canvis, reflexionant i avaluant la seva aplicació, ens ajuda a anar avançant en la consideració dels espais exteriors com educatius, i a poder descobrir els beneficis que suposa per a les criatures el joc i l'activitat a l'aire lliure en contacte directe amb la natura. 


\title{
Per què és tan necessària la transformació dels patis
}

Durant moltes generacions, jugar a l'aire lliure, ha estat habitual per a les criatures. Els seus punts de trobada eren el carrer, el pati, el solar o el parc. Espais de joc i de socialització. Per a moltes de les mestres, avui ja grans, la primera escola va ser el carrer. Un lloc viscut intensament on el joc i les relacions potenciaven i feien créixer la nostra curiositat per descobrir, inventar, crear. Llibertat per poder jugar i retrobar amics de diferents edats. Espais on apreníem i conqueríem la nostra autonomia.

Ara, els temps de pandèmia que estem vivint ens han posat a prova per continuar el que estàvem fent en la recerca dels canvis necessaris a l'escola, defensant els drets i les necessitats dels infants, els nostres espais i la nostra salut.

En les àrees metropolitanes, veiem molt reduïts els llocs de joc i es va perdent el coneixement dels jocs infantils espontanis a l'aire lliure. D'una forma accelerada es produeixen canvis en la nostra societat, Anna Serra, antropòloga, del grup de treball «Com està el pati?» de l'Associació de Mestres Rosa Sensat de Barcelona, en un recent article ens fa reflexionar i observar:

\begin{abstract}
«Actualment, però, en la nostra societat, ens trobem amb nens i nenes que, a diferència dels d'unes dècades enrere, tenen molta dificultat per jugar, divertir-se i relacionar-se en el mateix entorn i amb les mateixes propostes on ho havien fet altres generacions. Cada vegada més, els espais exteriors son percebuts com entorns perillosos i avorrits per als nens i les nenes, als quals se'ls treu dels espais públics i se'ls reclou en espais privats on passen moltes hores davant de pantalles». (Serra, 2019)
\end{abstract}

Els patis de les escoles, tant a les ciutats com als pobles, acostumen a ser espais generalment plans, ocupats majoritàriament per pistes esportives. Es caracteritzen per tenir molt ciment, plàstic, cautxú i gairebé sense ombra. Amb molt poc marge per a la seva transformació per les rígides normatives que imposen molts municipis al-legant «la seva homologació» o les seves contradictòries normes sanitàries. El joc que ofereixen no respon als diferents rols i necessitats de les criatures. Son espais monòtons, amb poques oportunitats de joc, poc coeducatius, en els què les criatures solen practicar activitats de moviment i agitació monopolitzades pel «joc de la pilota». On sovint es produeixen conflictes i en alguns casos l'abús o l'assetjament del més fort, del més poderós que aconsegueix el que vol.

Durant molts anys aquests espais han passat desapercebuts, tant pels aspectes de manteniment, com pels educatius i d'aprenentatge. No s'han considerat espais amb les seves potencialitats, acceptant el conflicte silenciós. El ciment, el cautxú i l'hort com a eixos contradictoris d'un paisatge «uniformat». Jocs limitadors per a moltes criatures que pateixen en silenci.

\section{Realitats descrites per Anna Serra:}

\footnotetext{
«En les meves observacions del pati d'infantil de l'escola Pau Vila del Papiol, vaig constatar que el curs 2016-17, l'índex de conflictivitat dels alumnes s'havia més que doblat respecte al que havia observat entre els anys 2005 i el 2008, passant d'observar 0,81 discussions i / o conflictes al dia, a 1,7. Augment que es produeix en paral-lel amb l'elevat increment de l'ús que els nens fan de la televisió, videojocs, ordinadors o internet, el qual en tan sols 9 anys ha augmentat un 27\% l'estil d'oci sedentari entre la població dels 3 als 14 anys. Aquest nou estil de vida fa que els nens tinguin moltes dificultats per desenvolupar les seves capacitats imaginatives i de relacionar-se amb els seus iguals. Alhora que, realitzant aquest tipus d'oci sedentari, ens trobem amb unes xifres cada vegada més alarmants d'obesitat infantil...»
}

«... Però l'alarmant dificultat dels nens a l'hora de realitzar jocs de qualitat, d'establir relacions amb els seus iguals, de realitzar exercici físic i tenir contacte amb la natura, fa que una part de la societat estigui convençuda que ha arribat el moment de fer canvis importants. Perquè si el que realment es vol és crear espais 
on els nens gaudeixin, interactuïn amb altres persones, es moguin i aprenguin, els parcs i patis han de transformar-se». (Serra, 2019)

La pèrdua d'autonomia infantil ha fet que, per primera vegada en la història dels països desenvolupats, la infància hagi perdut el joc lliure. L'únic que tenen és el pati i el parc de jocs i tots dos tenen un disseny pèssim que no permet ni la socialització ni la varietat de jocs necessària. És, per tant, una doble negació que converteix el problema en urgent.

\section{Una nova visió del pati de l'escola}

L'articulació de l'espai exterior de l'escola ha de ser el resultat d'un intercanvi intens entre la pedagogia, l'arquitectura i el projecte educatiu que defensem, creant i estructurant recorreguts diversos que convidin a escollir, a provocar; que convidin a pensar. El concepte pedagògic ha de ser la base per transformar el pati en un lloc de vida, pensat perquè pugui ser un espai habitable durant totes les hores del dia. Pensat per a totes les edats i necessitats específiques de les diferents etapes educatives. Partint dels drets de l'infant reconeguts en el primer principi pedagògic de l'Escola de bosc de Barcelona creada el 1914 i dirigida per la mestra Rosa Sensat:

El coneixement de l'infant i el respecte de la seva personalitat i dels seus drets han de ser els eixos sobre els quals ha de girar l'educació (González-Agàpito, 1989).

I dels que reconeix la Convenció sobre els Drets dels Infants (UNICEF, 1990).

Espais que acullin naturalesa, salut, creativitat, convivència, ciència, comunicació, escenaris acompanyats d'interessos i aprenentatges. Les nenes i els nens necessiten per al seu desenvolupament llocs «sensorials» en els quals poder experimentar i processar el que viuen amb els seus iguals.

Disposem de suficients arguments científics i pedagògics que posen de manifest el gran valor d'aquests espais. Recuperem els grans referents i els seus principis que ens parlen del benefici d'apropar els nens a la natura. Rousseau, Pestalozzi, Fröbel. El naturalisme pedagògic, l'experimentació, l'acció dels nens per sobre de la paraula i el contacte amb la natura com a punts claus en la seva educació. Julián Sanz del Río i Francisco Giner de los Ríos, impulsors del krausisme a Espanya i fundadors de la Institución Libre de Enseñanza (ILE), posen en contacte directe l'alumne amb la natura i amb qualsevol objecte de coneixement, d'aquí la importància de les classes experimentals i de les excursions. Així també ho van fer, entre d'altres, Maria Montessori, les germanes Agazzi o Rosa Sensat. Aquesta última deixebla de la ILE i directora de l'Escola de Bosc de Montjuïc, una de les primeres escoles de bosc de Barcelona.

\section{Imatge 2: Escola bressol municipal Els belluguets de Palafurgell}

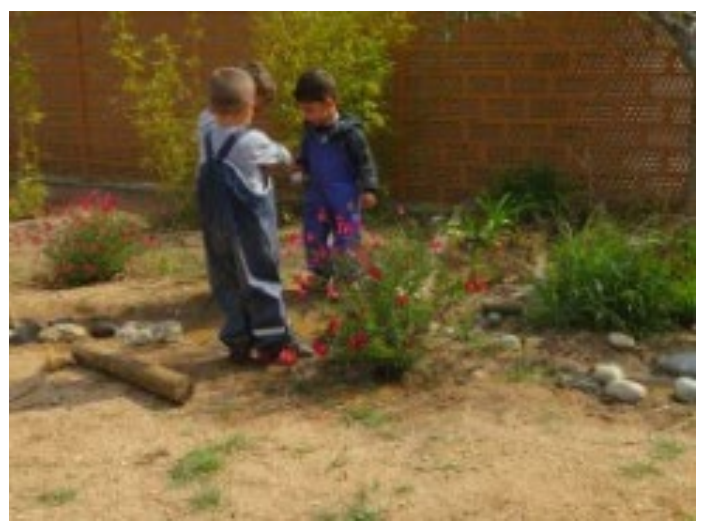


En tractar-se d'un espai a l'aire lliure, en una nova articulació del pati, la presència de naturalesa passa a tenir un paper important ja que amb ella s'aconsegueix un entorn acollidor, de salut i benestar, fent-lo habitable i apropiat per a la creació de múltiples escenaris i situacions que no diguin a les criatures el que han de fer i els facin pensar, escollir, decidir, a què vull jugar? què vull fer? amb qui ho vull compartir? quant de temps necessito? Baixant la velocitat, l'estrès i respectant els temps necessaris per al joc. Cada vegada és més conegut el benefici que suposa per a les persones el contacte amb la natura. Heike Freire ens ho planteja en el seu llibre Educar en verd i, des de la psicologia ambiental, Silvia Collado i José Antonio Corraliza afirmen:

\begin{abstract}
«Durant molts anys s'ha intuït que el contacte amb la Natura té efectes beneficiosos, tant físics com psicològics per als éssers humans. Aquesta simple intuïció ha estat corroborada per la investigació empírica duta a terme durant les últimes tres dècades. Els investigadors han demostrat que passar temps en contacte directe i / o visual amb la Natura ofereix efectes positius per als éssers humans» (Collado i Corraliza, 2016, p. 43).
\end{abstract}

\title{
I Anna Serra proposa:
}

\begin{abstract}
«Així doncs, la creixent corrent de molts sectors relacionats amb la infància que defensa la transformació dels espais exteriors, podria ajudar a donar resposta a la necessitat urgent de reconduir aquesta tendència i aconseguir que els nens surtin dels espais privats i tancats, i recuperin l'espai exterior on poder realitzar activitat física; interaccionar amb altres persones; afavorir la creativitat i la resolució de problemes; i recuperar el contacte i la interacció amb la natura». (Serra, 2019)
\end{abstract}

Entorn a la natura, petits i grans busquem el plaer de jugar, treballar, parlar, pensar i inventar junts en la construcció d'un projecte educatiu.

\section{La integració de l'espai exterior de l'escola en el projecte educatiu}

Un projecte que parteix de l'entorn social, cultural i natural en què l'escola està ubicada, tenint en compte tots els seus espais, traspassant parets i integrant l'exterior i utilitzant tots els recursos possibles per crear arrelaments al territori. Espais i temps per escoltar, per crear, per parlar, per construir, per elaborar petits i grans projectes comunitaris.

Un projecte educatiu viu i actiu on hi hagi debat sobre la vida de l'escola. Un document que es va modificant des de la reflexió i adaptant-se a les realitats i a les persones per donar oportunitats de participació. Respectant el temps necessari per anar creixent amb els diferents estaments de la comunitat: nens, mestres, famílies i representants de l'administració.

Un espai i un temps necessaris per a la formació en la diversitat de disciplines que hi intervenen, cuinant a foc lent amb els ingredients necessaris en cada moment, on les necessitats de les criatures han de ser les protagonistes. Un projecte educatiu que servirà de guia i s'anirà fent visible a la vida quotidiana.

Una escola agradable, on nens, mestres i famílies es trobin bé, tant en l'espai interior com a l'exterior. Una escola que adapti la seva organització a les demandes actuals: espais, horaris, currículum, agrupacions, metodologies, materials, donant valor educatiu a tots els seus espais. Una arquitectura adequada a les característiques del seu projecte educatiu. Riquesa d'espais i ambients on poder dur a terme diversitat de propostes. Una organització del temps flexible que permeti estar en els patis sense aglomeracions. Espais que facin possible aprenentatges vitals, humans, competencials, donant resposta a la diversitat d'interessos i motivacions de tota la comunitat educativa. 
Un projecte educatiu que estableixi les bases per fer possibles espais educatius acoIlidors, comunicatius, empàtics, que donin veu a les criatures, capaços de generar ambients polisensorials, que creïn record, que donin possibilitat d'escollir, que reflecteixin uns valors ètics i estètics.

\title{
De pati a jardí
}

\section{Imatge 3: Escola pública Cavall Bernat de Barcelona}

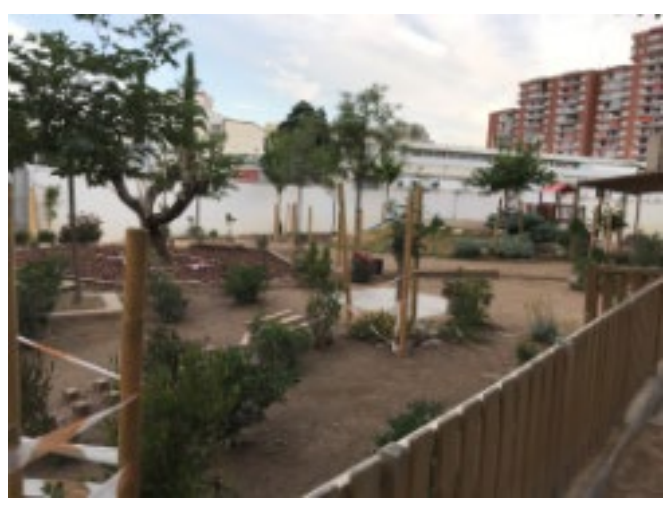

A fora, el pati de l'escola té un valor especial, potent, ple de records construïts per les generacions i noves trobades de persones nouvingudes. Espai obert a tots els sentits. És l'espai que més trepitgen les famílies, ple d'oportunitats per anar creant relacions: mestres-família, nens amb els seus amics de pati... És un lloc on trien els seus amics, organitzen, debaten, es plantegen reptes... L'espai exterior de l'escola permet aquesta dualitat: ser un lloc visible i escoltat des de molts punts i alhora ple d'oportunitats per al joc secret dels nens.

Pot ser l'entorn natural i el primer pulmó verd on haurien de passar més hores les criatures. No té sostre. Un entorn natural que acull el social i cultural. Un espai verd que permet prendre consciència i establir un contacte directe amb el món sensorial i els seus canvis. Un espai per a la investigació i l'aprenentatge, ric a partir de la interacció amb els materials i l'observació dels fets que hi passen. Sense cap finalitat didàctica, les criatures exploren movent pedres, fent recorreguts, recollint fulles, trobant bestioles.

\section{En les seves observacions l'antropòloga Anna Serra constata:}

\begin{abstract}
Naturalitzant els espais s'estimularà la curiositat, la imaginació, la fascinació i l'aprenentatge per descobriment, respectant el ritme de cadascú. Els elements naturals ofereixen reptes i complexitats que es modifiquen i es transformen amb el temps, fent que l'espai no sigui monòton i avorrit per als nens, alhora que fa créixer el seu respecte per la natura.

...en els patis amb més opcions lúdiques els nens estan més a gust perquè solen trobar espais que s'adapten a les preferències de cada un, i això queda palès amb la reducció del soroll i de la conflictivitat. (Serra, 2019)
\end{abstract}

Recuperant el paisatge i el joc natural, segons Bird:

disposar d'entorns interessants i atractius per jugar pot contribuir també a la reducció dels comportaments agressius i dels conflictes a les escoles. El comportament destructiu és més comú observar-lo en grans espais, avorrits, sense arbres, arbusts o altres delimitacions naturals. (Bird, 2007, p. 62)

\section{Claus Jensen proposa:}


A mi m'agrada la idea de repensar els espais interiors de l'escola com a espais oberts o com un lloc on es treballi al màxim perquè ho siguin. En una sola frase vindria a ser: un espai on no hi hagi murs, sinó obertura, i on els nens puguin anar de la seva classe o estança a una altra sense cap problema i moure lliurement entre els diferents espais.

Per tant, crec que és un gran repte i que s'ha de desafiar el sistema tradicional. Per aconseguir-ho, cal anar a la classe sense el pensament de tancar la porta i no deixar entrar. Considero que, si ens obrim i treballem de forma més oberta, segurament trobarem noves solucions.

Per exemple, si en una escola es decideix que és bo per als nens i nenes sortir fora, una manera d'organitzar-se seria tenint un mestre tot el dia fora, al pati i així els nens podrien entrar i sortir lliurement. Aquesta seria una nova manera d'organitzar-se i seguir un camí diferent. Si es té una estructura d'escola més rígida, amb temps i espais poc flexibles, llavors es fa més difícil pensar altres formes de fer i d'organitzar-se. Si tens una estructura flexible, els nens podrien i haurien de circular més entre el dins i el fora. (Jensen, 2018)

\title{
La transformació del pati
}

Les demandes per a la transformació del pati neixen des de diferents mirades i necessitats. L'inici d'un procés el protagonitza un petit col-lectiu de persones, que sovint son alhora mare i mestra, implicades en l'escola dels seus fills o en la seva, motivades i plenes d'emocions quan han de portar els seus fills a l'escola. De vegades escoltem la frase «el pati està igual que quan jo venia a l'escola» altres vegades escoltem «Han tallat tots els arbres, totes les zones tenien terra en la que jugàvem a bales i ara estan asfaltats o coberts amb cautxú». Observant els problemes i conflictes que en aquests empobrits espais es viuen i es perceben, els records sorgeixen, es manifesten amb les emocions a flor de pell i predisposen al canvi amb la inquietud de moure alguna cosa.

També ens trobem amb realitats, que lluny de desanimar-nos, ens fan pensar. Isabel León ${ }^{1}$, mare d'una escola de Madrid ens comenta:

\begin{abstract}
Avui ha estat un dia intens, estem veient propostes per millorar el pati a partir dels Pressupostos Participatius a Madrid, i sorprenentment el professorat ens ha lliurat les seves idees. Avui, més que mai, aquesta situació m'ha fet recordar les paraules de Carme Cols quan parla de la importància de la formació i més formació, o d'Inma i el seu projecte a Almudévar quan parla de la comunicació... Sent autocrítica, crec que hem fallat durant aquests 2 anys, quan veig que el centre rebutja plantar plantes o arbustos o posar sorra o instal.lar jocs de fusta i ens proposen aquesta gran idea: instal.lar al mig del pati un billar de futbol gegant! Sí, sí, sí, el que veieu, això és el que alguns mestres entenen per transformar el pati escolar que tots coneixem i entenem en aquest grup. Vull compartir-les perquè pot servir per a alguns dels vostres Power Point en les xerrades o conferències que doneu habitualment, crec que reforça la idea de perquè és necessària la formació.
\end{abstract}

Fer possible una iniciativa conjunta és el punt de partida necessari. Un camí gens fàcil si hi ha presses. Els errors formen part del procés i també ens eduquen si promouen la reflexió i el debat.

Cada experiència requereix el seu temps i en molts moments cal aturar-se per recuperar energies i lideratges positius. Els canvis profunds només es poden veure amb el temps. En un projecte com aquest, l'inici és clar, el final no existeix.

(1) Intervenció d'Isabel León, mare d'una escola de Madrid el 5 d'abril de 2019, compartida en el grup de Facebook Patios habitables. 


\section{L'experiència de l'escola pública Santos Samper a Almudévar, Osca}

Intervenció del grup «Un cole una ilusión» de la AMYPA Mariano Tomeo de l'escola pública Santos Samper d'Almudévar el dissabte 9 de febrer de 2019, a la jornada «Al recreo» sobre educació artística, paisatgisme i desenvolupament comunitari:

\section{Imatge 4: Escola Santos Samper d'Almudévar (Osca) abans}

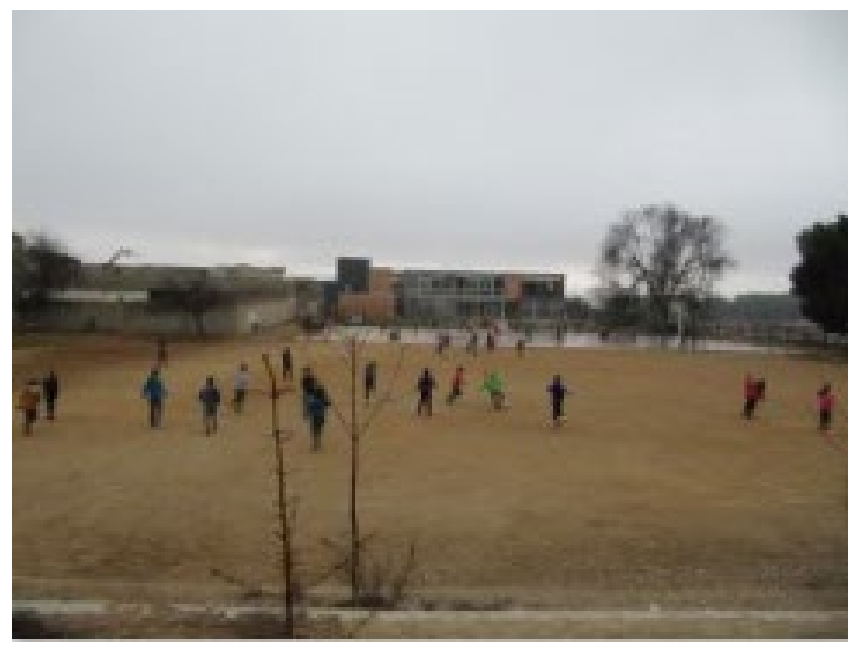

\section{Imatge 5: Escola Santos Samper d'Almudévar (Osca) després}

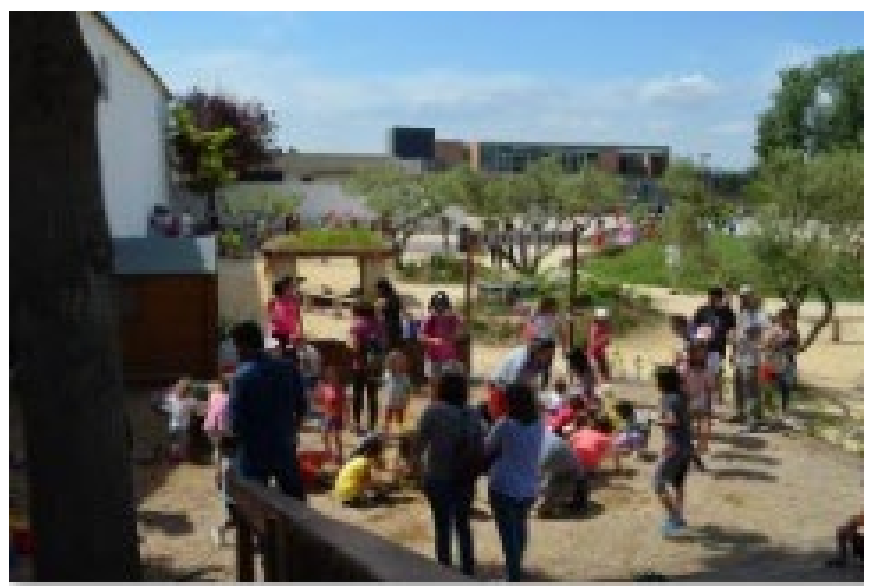

«L'inici va ser molt il.lusionant, va ser un moment de llegir i aprendre d'altres, i de conèixer-nos, amb tot el que anàvem fent. La realitat és que començàvem amb zero euros. Un grup va començar amb el disseny, ens formem, informem i documentem. Van venir Carme i Pitu, Alfredo Larraz i Javier Mendiara, tots mestres jubilats experts en el tema. Qüestionaris, famílies, docents, dibuixos dels nens. Hores de reunions i debats. Iván Pagnussatt, pare de l'escola, ens va fer una estupenda làmina que ens va permetre visualitzar el que volíem fer i donar-lo a conèixer. Organitzem moltes activitats per obtenir recursos i donacions: tarima, oliveres, maquinària d'HIDROMAN, calaixos i bobines de fusta. I de tota la gent, associacions o empreses que han col-laborat amb nosaltres per fer tallers, activitats a la festa, músics, fotos amb dron, muntatge de vídeo, donar-nos materials per sortejar... En aquest primer any es va crear un gran grup humà. Molt important, el valor social del projecte. El va crear el mateix projecte, però sobretot els esdeveniments que vam fer per obtenir finançament. Van ser uns mesos MOLT INTENSOS: finançament, disseny, elaborar el projecte, planificar obres, participar en els actes que organitzem... Molta intensitat! Massa, si mirem cap enrere... Però a l'abril de 2018 el verd va començar a brillar en el nostre pati. Al juny de 2018 vam celebrar la II jornada de convivència i joc de la comunitat educativa Santos Samper. Festa a l'escola, oci inclusiu i comunitari. Noves energies, petits objectius... Seguim fent petites actuacions: muntatge d'una estació meteorològica, dos elements de joc, una mica més de vegetació... El projecte segueix viu, però amb objectius 
diferents: dur a terme petites coses, manteniment, dinamitzar propostes i activitats en el pati... Els canvis profunds només es poden veure amb el temps. Un projecte viu, l'inici és clar, el final no existeix»².

\section{Imatges 6: Escola pública Santos Samper d'Almudévar (Osca)}
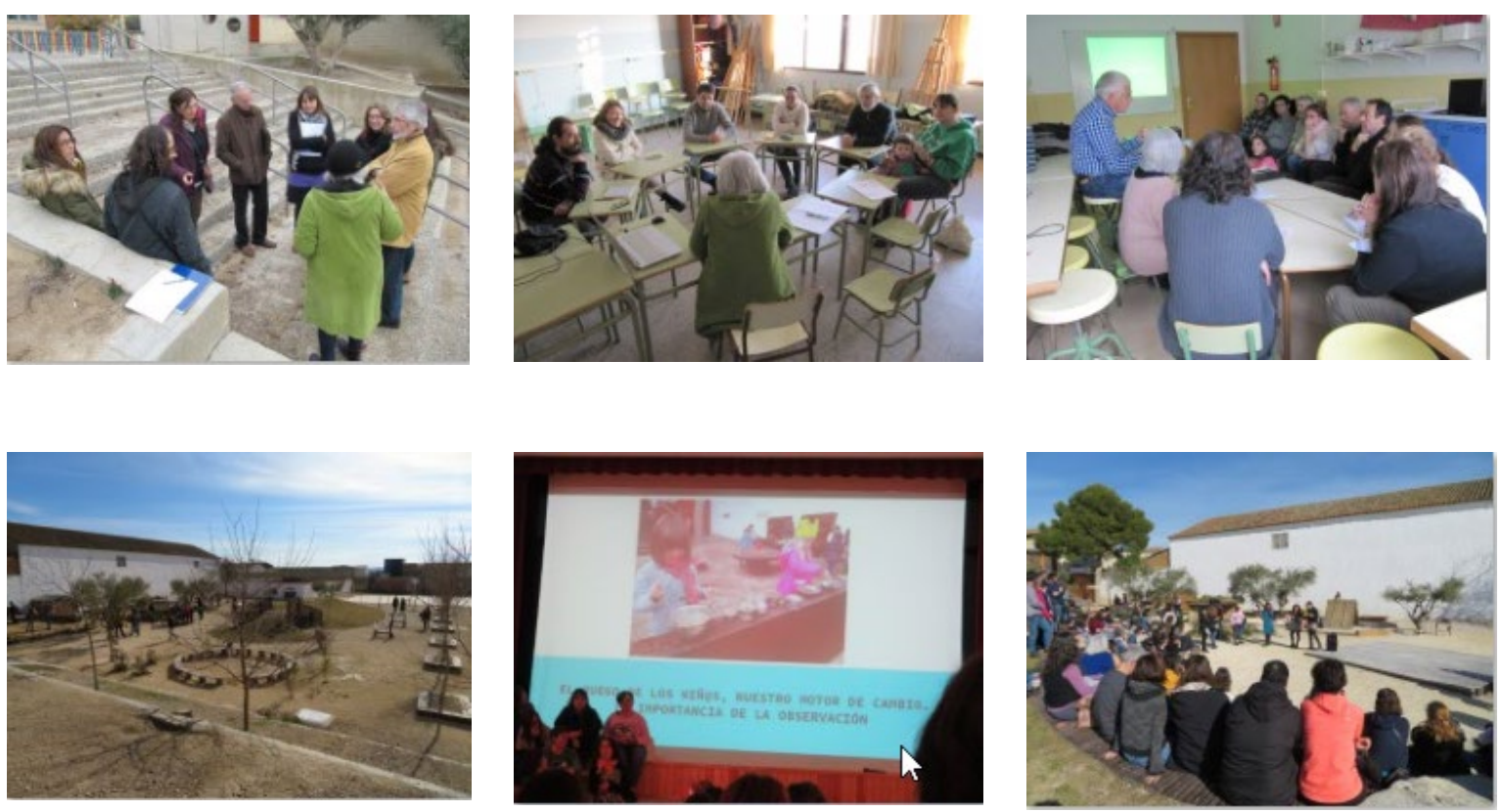

Veus sensibles que han iniciat aquest procés, però amb dificultats per fer-ho. II.lusions, accions potser acollides pel claustre com una intervenció, una participació puntual. Processos de vegades presentats com una intervenció per a la renovació amb pressupostos participatius des de l'administració local.

\section{Imatge 7: Escola bressol municipal Els Belluguets de Palafurgell}

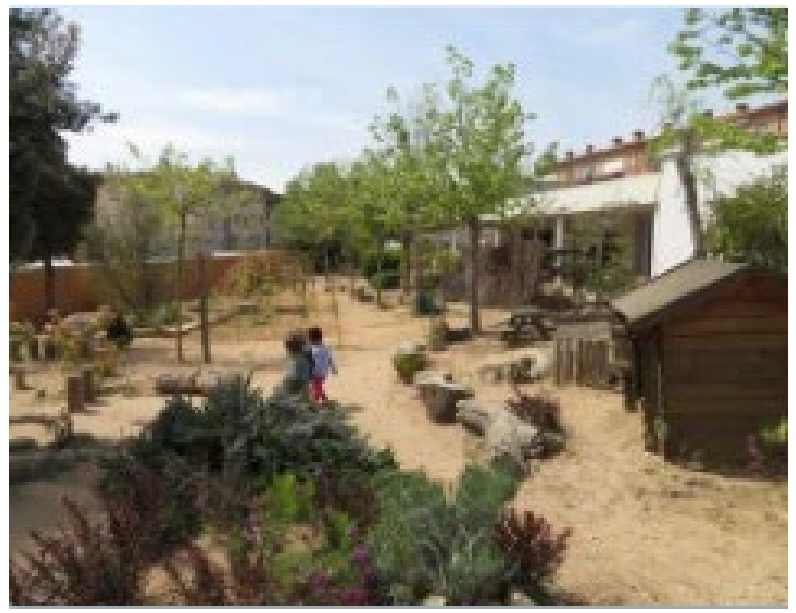

Moltes iniciatives que hem acompanyat neixen en les vivències de l'escola infantil 03 , un període sensible, ple de moments on es teixeixen fortes relacions entre grans i petits, mestres i famílies. Per respondre a les necessitats dels infants d'aquestes edats, avui

(2) Experiència recollida al blog elnousafareig.org el 14 de febrer de 2019, dins l'entrada «Almudévar, tres anys després». 
podem comptar amb moltes escoles que han fugit d'un concepte de nen sobreprotegit, amb paviments de cautxú i d'una estètica «Walt Disney» basada en joguines i mobiliari de plàstic i colors parxís, proposant a canvi espais pensats per a la conquesta de la seva autonomia en un mitjà sa i segur envoltats de natura. Les accions per crear espais més saludables han fet molt més potents les relacions i el coneixement entre les famílies. Un col-lectiu potent i lluitador que té moltes vegades continuïtat quan porten els seus fills a l'escola d'educació infantil i primària, trobant patis àrids i insalubres en els què volen intervenir per recuperar l'entorn natural. I que també comencem a veure a l'educació secundària.

Moltes realitats amb avenços significatius els vivim en iniciatives conjuntes, on trobem per una banda a mestres, famílies, regidors, alcaldes amb una doble funció com a ciutadans i responsables de gestionar aspectes socials i educatius de la ciutat. De l'altra, també un col-lectiu pluridisciplinari: arquitectes, paisatgistes, fusters, jardiners, artistes, biòlegs, tècnics de medi ambient $\mathrm{i}$ altres professionals que acompanyen $\mathrm{i}$ assessoren trobant l'essència d'aquest canvi en la investigació, el compromís de la comunitat i de l'administració, facilitant punts de referència, mitjans i formació per actuar. Realitats que comencen a posar de manifest la necessitat de persones a l'escola que tinguin els coneixements necessaris, pedagògics i tècnics, per a la gestió d'un espai exterior renaturalitzat.

\section{Observar, preguntar i interpretar les necessitats dels infants}

El procés de transformació uneix diferents interessos que arriben a l'escola a través de famílies i mestres i comença a materialitzar-se a partir de la implicació de les nenes i dels nens mitjançant un procés d'investigació, exposició i debats. Però al preguntar-los, detectem un problema que no ajuda a donar resposta a les seves necessitats.

Imatge 8: Consell d'infants de l'escola pública As Covas de Meñao (Pontevedra)

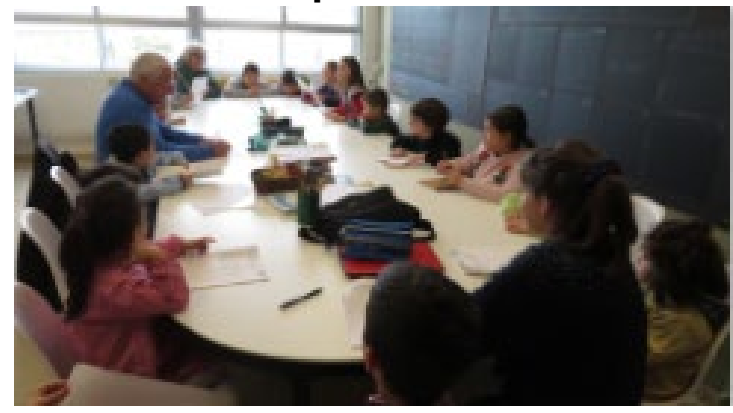

Imatge 9: Observant el que tenim i el valor de la seva natura a l'escola As Covas de Meñao

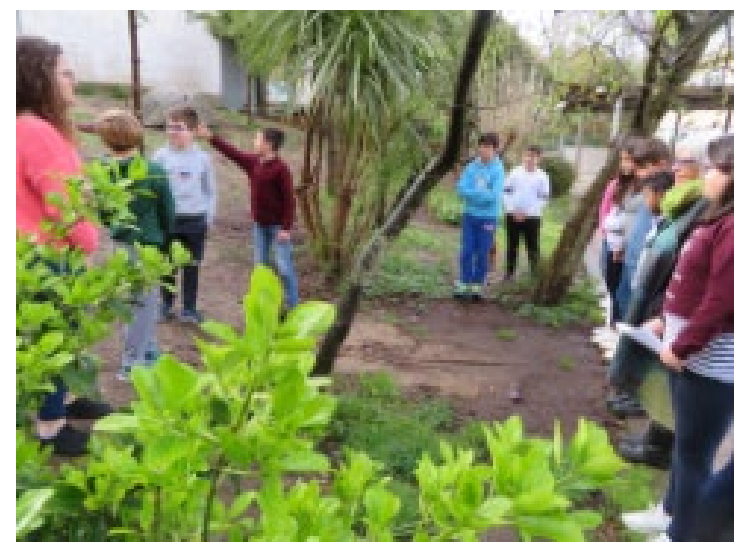


Preguntant què us agradaria tenir al pati? o com seria el vostre pati perfecte? sorgeix una llarga llista: una piscina, un tobogan d'aigua, pistes amb gespa... demandes molt estereotipades que provoquen expectatives i uns valors en una societat en què tot es compra o s'aconsegueix ràpidament i fàcilment, què comprarem? quant val? quan ho tindrem? En arribar al centre, en el nostre primer contacte ens pregunten: què ens porteu? Per a ells som els experts que farem possibles els seus somnis. I, en alguns casos, a les famílies i mestres els sembla que tenim una mena de vareta màgica per a un nou disseny. Tot un treball per reflexionar i cuinar a foc lent canvis profunds de valors. Com fer-los pensar més enllà del concepte de pati que sempre han viscut?

Camins de reflexió retrobant dues preguntes que ens va fer Phillippe Meirieu³:

«Quins nens deixem al món? Deixarem al món uns nens capaços de pensar i de reflexionar? O deixarem uns nens manipulats per una societat de consum que farà amb ells el que voldrà?».

En un context d'observació i pensant en com preguntar a les criatures per poder trobar respostes coherents amb el nou projecte, preguntes del tipus: Com podríem sentirnos millor al pati? Què ens agradaria conèixer? Trobarem a Internet experiències d'altres escoles? Què podríem construir? Com podríem investigar per tenir més ombra? Podríem pensar com utilitzar aquests espais per fer altres activitats? Qui ens podria ajudar? Ens poden obrir un ampli ventall i enriquir el diàleg per fer possible que els nens, com a protagonistes, siguin el motor del canvi.

Cada demanda ens fa investigar. En una de les nostres visites a escoles, preguntant a Víctor, un nen de sis anys que en la seva llista, entre altres coses, ens va proposar una fàbrica de ceràmica, per a interpretar la seva demanda li vam demanar què necessitaria. Es va quedar pensant, va demanar de nou paper i va dibuixar: una taula, un torn, un forn, una banyera plena de fang, una caseta... La seva proposta ens va generar noves preguntes: què hauríem de conèixer? com podríem crear objectes de ceràmica? com podríem tenir més informació? Tot un seguit de qüestions a les que en aquell moment, abans de marxar, no vam poder donar-hi una resposta concreta. Uns dies després vam recordar una experiència viscuda en una escola infantil de la ciutat danesa d'Aarhus en la que els infants creaven figures amb el fang del pati per coure-les en una foguera i exposar-les en les prestatgeries d'una caseta al costat dels tresors que anaven trobant en el seu entorn natural. Ens vam comunicar amb el pare d'en Víctor, arquitecte i membre de la comunitat educativa que ens havia convocat, per explicar-li que la proposta del seu fill era tan clara que ens va fer recordar els moments viscuts en aquella escola, i li vam fer arribar mitja dotzena d'imatges. Aquesta va ser la seva resposta:

M'ha encantat, i per suposat que ha encantat al meu fill!!! Està molt il.lusionat amb la transformació del pati... i està desitjant començar... La veritat és que no cal complicar-se gaire per fer qualsevol cosa... la senzillesa és la clau de l'èxit en aquest cas, a més de fer partícips als infants (que és fonamental per a ells).

\section{La comunitat s'ha d'implicar}

Com aprenem a gestionar un grup de persones? Aquest és un altre repte al qual ens enfrontem i que hem de resoldre amb actituds d'escolta i respecte. Preguntes senzilles en un inici per obrir el diàleg entre diferents maneres de fer i pensar. En una comunitat, d'una

(3) En la seva ponència «Quin infants deixarem al nostre món?» a la II Jornada Marta Mata, organitzada per la Fundació Àngels Garriga, el 14 de novembre de 2009. 
forma natural van apareixent lideratges. Lideratges conscients, positius, que saben delegar i confiar en les possibilitats de cada grup o comissió. Abordant els reptes que es presenten. Lideratges que s'eixamplen i saben formar grups trobant solucions a diferents problemes que puguin anar apareixent, trobant la complicitat d'altres perfils professionals del món de l'educació, de l'arquitectura, de la jardineria, que comparteixin la visió d'aquests espais de formes diferents, més oberta i centrada en les necessitats dels infants i de la comunitat educativa de l'escola, d'ara i del futur. Diferents mirades que ens uneixen en una cultura d'investigació.

L'escola és un espai que afavoreix trobar maneres de compartir coneixements des de diferents llenguatges amb la riquesa i els matisos que una comunitat aporta. Els mestres han de ser uns grans coordinadors per acollir, abraçar i potenciar la utilització d'aquests espais, donant-los visibilitat mitjançant la documentació. Famílies i mestres van creant condicions per mirar i veure una nova educació construïda dia a dia. I una escola arrelada, que té un paper significatiu en el seu barri, poble o ciutat. Una escola que va més enllà dels murs, oberta a les coses que passin dins i fora. Una escola on es produeixen intercanvis de relació entre molts adults i moltíssims nens. Una escola viatgera, com deia Loris Malaguzzi:

\footnotetext{
...una construcció viatgera, en ajust continu, basada en les dinàmiques interactives dels seus protagonistes i de les seves capacitats de combinació, on cadascuna de les parts es mou amb la seva identitat i els seus deures, trenant Iligams de reciprocitat i cooperació (Malaguzzi, 1996, p. 12).
}

Processos i criteris que dibuixen i van configurant les intencions d'un projecte educatiu en el qual creiem i que defensem. Espais creats per acollir la diversitat, cohesionant el collectiu. Llocs generadors de sentiment de comunitat, d'identitat, de pertinença a un grup en què han pogut participar. Cooperatius, interactius, singulars, amables, acollidors, que conviden a quedar-se i a ser utilitzats en l'ús comunitari.

Un camí gens fàcil i ple d'incerteses. Vivim una època en què la millor actitud per aprendre és desenvolupar la capacitat d'adaptació a noves realitats. Abordar les dificultats que van apareixent durant el procés ens permet generar habilitats per respondre i fer-nos noves preguntes. En els equips pedagògics i amb les famílies. Aprenent a manejar molts aspectes que desconeixem. Necessitem temps de debat intern sols o acompanyats per ajudes externes en diferents disciplines. A la recerca d'un nou paradigma cal sortir de les individualitats donant resposta a les necessitats col-lectives a partir de la corresponsabilització, de les experiències i sabers de la comunitat construint criteris, valors i accions.

El resultat de tot això ens ha ajudat a anar definint el que volem que passi a l'espai exterior de l'escola i anar configurant alguns criteris per a la seva articulació.

\section{Criteris de funcionalitat}

- Zones diversificades que suggereixin camins, creant itineraris en un entorn que permeti fer vida i crear continuïtat entre l'interior i l'exterior.

- Crear ambients en harmonia que suggereixin, que invitin, que provoquin la seva utilització, tenint en compte la tridimensionalitat de l'espai.

— Paviments amb diferents textures per a jocs de moviment, de repòs, de silenci.

- Espais per a trobades en diferents tipus d'agrupacions: àgora, taules i bancs. 
- Llocs d'experimentació lliure o acompanyats creant petits o grans projectes, per conrear, per observar, creant petits ecosistemes.

- Fonts per beure. Papereres tenint en compte el reciclatge.

- Bancs que delimitin, que convidin al repòs, a la trobada, a l'observació.

- Llocs i materials per poder crear aventures: cabanes, rius, enfilar-se.

- Espais que uneixen esport i natura. Pistes polivalents per oferir oportunitats de salut conscient, psicomotricitat, practicant esports diversificats, per patinar, per anar amb bicicleta, etc.

- Espais oberts a la comunitat, al barri, al poble, per trobar-se i ser utilitzats quotidianament i en altres moments: festes, celebracions o esdeveniments culturals.

- Materials solts (loose parts) que inspirin propostes de joc i construcció: fustes, caixes, troncs, teles i altres interessants que pugui aportar la comunitat.

\section{Criteris sobre l'entorn natural}

- Utilitzar la vegetació com a element indispensable per a la creació d'un entorn de salut i benestar. La vegetació crea una atmosfera. És bella, és útil.

- Retornar al pati la naturalesa autòctona del seu paisatge. Reconèixer els ecosistemes i els entorns naturals de la zona i recuperar-los reflectint la seva identitat i la seva cultura amb la voluntat de gaudir de paisatges de qualitat i de tenir un paper actiu en la seva transformació. Com s'expressa en el Conveni europeu del paisatge:

«Protegir, gestionar i planificar el paisatge implica drets i responsabilitats per a tots» .

- En aquest sentit el Paisatge esdevé un magnífic recurs pedagògic que pot servir al desenvolupament de la sensibilitat dels nens i de les noves generacions perquè tinguin cura del paisatge i entorn futurs.

- Introduir la vegetació autòctona és imprescindible realitzant una planificació de les zones creades pensant en qui i a quines edats es destina el pati i els espais, tenint en compte l'entorn físic, social i paisatgístic.

(4) El Conveni europeu del paisatge va ser ratificat pels Estats membres del Consell d'Europa l'any 2000. És el primer tractat internacional que promou el desenvolupament sostenible que es fonamenti en un equilibri harmoniós entre les necessitats socials, l'economia i el medi ambient. 


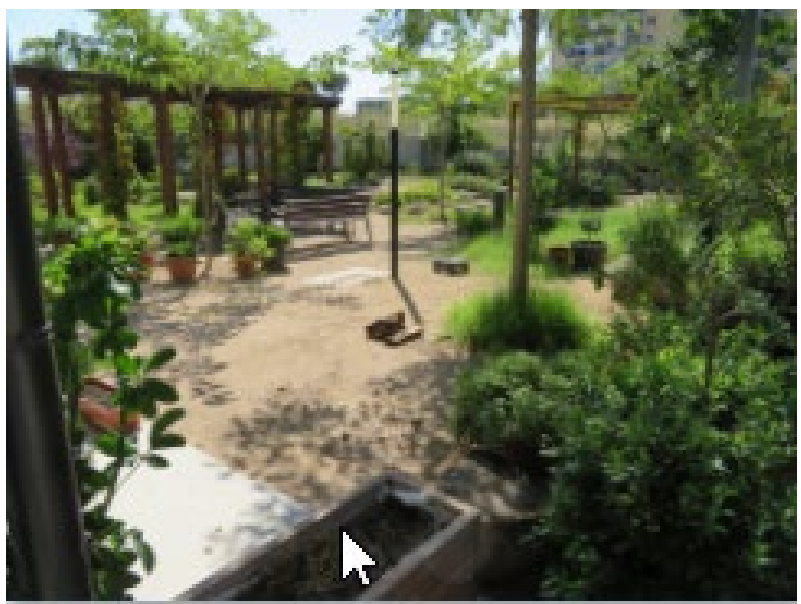

- Arbres, arbustos, enfiladisses i plantes han de donar forma a l'espai d'una manera orgànica. Per crear bellesa, ombra, baixar la velocitat, crear recorreguts.

- Un espai verd, atractiu, provocador. On la naturalesa pugui projectar sons, colors, textures, olors... Un paisatge canviant de vida activa que els nens i nenes recordaran com un referent en la seva memòria.

- Tenir en compte la sostenibilitat de les espècies escollint les més adequades i menys exigents.

- En aquest espai renaturalitzat, un nou perfil professional, tallerista-jardiner permanent podria tenir-ne cura, observar els processos de la natura i acompanyar els infants en els seus projectes. Fent possible que l'espai sempre estigui obert i disponible per acollir els infants respectant els diferents ritmes i facilitant les activitats de l'espai interior.

\section{Criteris tècnics, estètics i de manteniment}

Imatge 11: Prenent consciència del que representa el paviment de cautxú a l'escola pública As Covas de Meaño (Pontevedra)

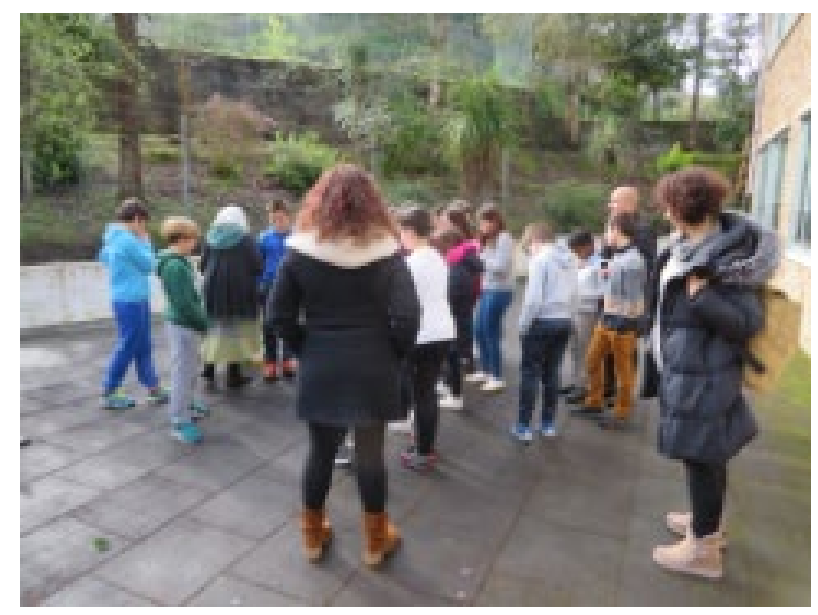

- Crear les diferents propostes amb criteris estètics i amb senzillesa, confort i seguretat, sabent el que no volem: tanques i corralets, colors infantilitzats; parets pintades de forma precària; materials sintètics: paviments de cautxú, joguines i estris de plàstic poc saludables i exposats al deteriorament amb el pas del temps. 
- Organitzar les tasques de cura i manteniment amb la implicació dels diferents sectors de la comunitat educativa. La dels nens i nenes en els seus processos d'aprenentatge sobre el medi natural i la seva protecció. La de l'equip de mestres integrant aquestes tasques en el projecte educatiu i en l'organització de la quotidianitat. I la de persones del sector familiar, especialment la de professionals: tècnics de medi ambient, jardiners, paisatgistes i altres competents en aquests temes.

- Utilitzar serveis i recursos de proximitat tenint en compte el benefici i la qualitat que pot suposar per a la comunitat la complicitat amb les institucions i el comerç local.

- Assegurar la riquesa i manteniment necessàries dels sòls per a la salut de l'arbrat i de la resta de la vegetació del pati. La riquesa del subsol donarà vida i continuïtat al futur de les plantes.

- Sabent que la majoria dels patis pateixen de manca d'ombra en els mesos més calorosos de l'any, s'ha de preveure la plantació dels arbres que es considerin necessaris. Un punt crucial i urgent tenint molt en compte la climatologia de les diferents zones.

- Reservar l'ús de tendals al temps en què es desenvolupa el creixement dels arbres. Utilitzar els mínims possibles fins que els arbres generin la seva ombra i contribueixin a la disminució de la temperatura ambiental.

- Utilitzar sistemes de reg per a l'estalvi d'aigua. Assegurar un correcte drenatge perquè, en cas de pluja, els cursos d'aigua flueixin cap al clavegueram o cap a basses de drenatge on aquesta es vagi filtrant de mica en mica, enriquint els aqüífers, i oferint la possibilitat de joc i experimentació per part de les criatures.

- Treballar a favor de la natura, amb tècniques de permacultura, observant la dinàmica dels ecosistemes per respondre de la millor forma a les necessitats de les plantes.

- Tenir en compte la seguretat de les diferents propostes: vegetació, jocs, desnivells, altures, etc. comprovant el compliment de les normatives de la Unió Europea UNEEN 1176 i 1177 sobre Seguretat a les àrees de joc infantil publicades a Espanya per ENAC (Entidad Nacional de Acreditación). En aquest sentit, l'acompanyament del municipi o la certificació per part de professionals o empreses qualificades pot assegurar l'homologació corresponent de les transformacions realitzades.

\section{Per concloure}

L'espai exterior ha de potenciar el joc a l'aire lliure com a essència bàsica per a les nenes i nens. Un laboratori d'aprenentatges on interactuar amb els elements naturals i amb tots els sentits. Escenaris, ambients provocatius, intel-lectuals, sensorials, emocionals, socials, actius, vitals, divertits, especials, útils, festius, segurs i cuidats.

Amb possibilitat d'escollir, córrer, caminar, seure, descansar trobant camins per recórrer i conviure, amb cadira de rodes o altres dificultats físiques o psíquiques. Espais que no incapacitin a ningú, obrint portes, traspassant murs que deixen entrar i sortir experiències colllectives.

Mirades compartides de sabers que cadascú pot aportar al voltant d'un projecte per fer de l'escola un espai de vida. Conscients que cada petita actuació serà un pas que farà possible el següent. Sense presses, però procurant elaborar un projecte global continu i 
dinàmic a curt, mitjà i llarg termini per poder anar-lo desenvolupant en petites intervencions.

Els processos compartits, en comunitat, uneixen sensibilitats i contribueixen a la co-

\section{El pati, un lloc que ...}

- Parla del capital humà, de la vida, de la sensorialitat i de la bellesa de les percepcions.

- Facilita la vida col-lectiva, individual i participativa.

- Fa visible una ètica i una estètica com a valors i aspectes fonamentals del projecte educatiu.

- Està pensat per a la seva funcionalitat i sostenibilitat, el seu ús, la seva accessibilitat.

- Facilita la flexibilitat d'horaris i d'utilització, acull la diversitat i la fa visible.

- Al que s'ha d'observar i documentar per donar importància al que passa.

- Permet dissenyar estratègies d'aprenentatges globals, transversals, per donar resposta a les necessitats de la comunitat educativa.

- Proporciona aprenentatges vitals: socialització, salut, creativitat, comunicació, ciència i cultura.

hesió del col-lectiu i a la millora de l'educació en general apostant per una escola de qualitat, compensatòria de les desigualtats socials i lluitant pel dret a l'educació per a tothom. L'escola, com a institució, necessita obrir les seves portes acollint les necessitats de canvi que avui la nostra societat reclama. Els canvis en els patis es van produint mitjançant un procés social, cultural, ambiental que va del dins al fora i del fora al dins, espais en diàleg constant. Un reflex de la societat que ha d'avançar conquerint els conceptes de fons sense quedar-se a la superfície. Una demanda, un desig de canvi que posa en relleu la necessitat de dignificació d'aquests espais des de la corresponsabilització.

L'acompanyament a les demandes amb xerrades, visites, conferències i escoles d'estiu ens ha portat a compartir molts projectes. Agraïm la generositat de tanta gent que ens ha obert les seves portes. Especialment a moltes que inicialment pensaven en fer «uns canvis físics» i amb les que a partir de l'observació i l'escolta dels nens i de la comunitat educativa hem pogut viure un procés que ha anat molt més enllà d'un simple canvi superficial per iniciar el camí d'una transformació pedagògica.

Acabem amb les paraules molt significatives d'un dels pares que ens van demanar ajuda i que representen a moltes comunitats que estan realitzant processos similars.

Finalment, volia aprofitar per agrair-vos la col-laboració en aquest projecte, que va sorgir com una idea puntual de fer quatre intervencions al pati perquè els nens tinguessin més recursos. Però que, gràcies a que l'escola es va obrir a la participació i va acollir la idea, l'Ajuntament ens va donar suport i ens ofereix l'oportunitat de participar de la definició del projecte. Des de les famílies ha sorgit gent amb ganes, energia i molt coneixement, tenim al davant un projecte molt estimulant, que segur aportarà un gran benefici als nens.

\section{Referències}

Bird, W. (2007) Natural Thinking. Royal Society for the Protection of Birds. 
Collado, S. i Corraliza, J.A. (2016) Conciencia ecológica y bienestar en la infancia. Madrid, Editorial CCS.

Cols Clotet, C. (2007) «Organitzar i viure els espais». Infància: educar de 0 a 6 anys, núm. 157, p. 12-19.

Cols Clotet, C. i Pitu Fernàndez (2016) «A fora. Articular un espai exterior, un procés col.lectiu». Infància: educar de 0 a 6 anys, núm. 212, p. 7-10.

Cols, C., Sargatal, E. i Fernàndez, J. (2012) «Els temps i els ritmes de la naturalesa». Infància: educar de 0 a 6 anys, núm. 188 p. 18-22.

Conveni Europeu del Paisatge. Consell d'Europa. Florència (20/10/2000) https://www.mapa.gob.es/es/desarrollo-rural/planes-y-estrategias/desarrolloterritorial/09047122800d2b59_tcm30-421584.pdf [Data consulta 29.12.2020]

Ferrière, A. (1929) Transformemos la escuela: Llamamiento a los padres y a las autoridades, Barcelona, Publicaciones de la Fraternidad Internacional de Educación. Segona edició.

Freire, H. (2011) Educar en verde. Barcelona, Editorial Graó.

González-Agàpito, J. 1989) Rosa Sensat i Vila, fer de la vida escola. Barcelona. Edicions 62.

Hueso, K. (2019) Jugar al aire libre. Barcelona, Plataforma Editorial.

Jensen, $C$. «Els mestres han d'anar a la classe sense el pensament de tancar la porta»

(Barcelona, Fundació Periodisme Plural) Disponible a: http://diarieducacio.cat/escolaestiurosasensat/2018/07/09/claus-jensen-elsmestres-han-danar-a-la-classe-sense-el-pensament-de-tancar-la-porta/ [Data consulta 09.07.2018]

Malaguzzi, L. (1996) La educación infantil en Reggio Emilia. Barcelona, Octaedro/Rosa Sensat.

Meirieu, Philippe Ponència «Quins infants deixarem al nostre món?» a la II Jornada Marta Mata, organitzada per la Fundació Àngels Garriga, el 14 de novembre de 2009. https://fundaciomartamata.org/docs/Quins-infants-deixarem-al-nostre-mon.pdf [Data consulta 14/11/2009]

Serra, A. «Per què és tan necessari transformar els espais de joc?» El Diari de l'Educació (Barcelona, Fundació Periodisme Plural) Disponible a: http://diarieducacio.cat/perque-es-tan-necessari-transformar-els-espais-de-joc/ [Data consulta 04.02.2019]

UNICEF Comité español. Madrid. Convención de los derechos del niño, 1990 


\section{Una nueva visión de los patios escolares}

Resumen: El espacio del patio es una ventana abierta al mundo. Su planteamiento nos permite intuir la vida de la escuela desde puntos de vista y aspectos diferentes. Es uno de los primeros espacios en el que las familias se fijan para escoger escuela. Un espacio emotivo por las percepciones y los recuerdos que la mayoría de los adultos han vivido. Es un espacio comunitario y una puerta abierta a la participación en el municipio como territorio colectivo. Puede ser un lugar en el que la naturaleza articule y haga visibles diferentes zonas, invitando a ser habitado y ofreciendo la posibilidad de compartir experiencias en un ambiente rico en posibilidades de juego, de aprendizaje, de relaciones, de convivencia, de creatividad. Un espacio de vida y para la vida en el que apostamos por hacer posible una escuela agradable, donde niños, maestros y familias se encuentren bien, tanto en el espacio interior como en el exterior de la escuela.

Palabras clave: Espacio educativo, patio escolar, organización, comunidad educativa, naturaleza, paisajismo, arquitectura

\section{Une nouvelle vision des cours d'école}

Résumé: L'espace de la cour est une fenêtre ouverte sur le monde. À partir de son approche, on peut se faire une idée de la vie de l'école sous des angles différents. C'est l'un des premiers espaces auxquels les familles font attention lorsqu'elles choisissent une école - un espace émotionnel pour les perceptions et les souvenirs vécus par la plupart des adultes. C'est un espace communautaire et une porte ouverte à la participation à la municipalité en tant que territoire collectif. Ce peut être un lieu où la nature articule et met en valeur différents espaces, invitant à être habité et offrant la possibilité de partager des expériences dans un environnement riche en possibilités de jeu, d'apprentissage, de relations, de coexistence et de créativité. Un espace de vie et pour la vie dans lequel nous nous engageons à rendre possible une école agréable, où enfants, enseignants et familles se sentent bien, tant à l'intérieur qu'à l'extérieur de l'école.

Mots clés: Espace éducatif, cour d'école, organisation, communauté éducative, nature, aménagement paysager, architecture

\section{A new vision of the schoolyard}

Abstract: The schoolyard is an open window to the world. The design of the schoolyard is an expression of the school's life from different points of view. Families consider the schoolyard one of the most important variables for choosing a school. It is an emotional space and most adults have strong memories of their schoolyards. It is a community space and an open door to participation in the municipality; it is a collective territory. The schoolyard can be a place connected with nature, making several areas visible, inviting participation and offering the possibility of sharing experiences in an environment rich in possibilities for play, learning, relationships, coexistence and creativity. It is a space of life and for life to have a pleasant school, where children, teachers and families feel good in the inside and outside spaces of the school.

Key words: Educational space, schoolyard, organization, educational community, nature, landscaping, architecture 